\title{
Serum osteoprotegerin and cardiometabolic risk factors in overweight and obese children
}

\section{Type}

Research paper

\section{Keywords}

children, osteoprotegerin, cardiovascular risk factors, excess fat mass

\begin{abstract}
Introduction

Osteoprotegerin has been shown to play a role in vascular calcification, atherosclerosis and the pathogenesis of cardiovascular diseases. We aimed to evaluate whether excess fat mass affects serum osteoprotegerin concentrations and to evaluate its associations with chosen cardiometabolic risk factors in overweight and obese children.
\end{abstract}

Material and methods

We enrolled 105 children ranging from 7.0 to 17.8 years of age. Among them 70 individuals were overweight and obese, and 35 were healthy with normal physical parameters. In all patients, anthropometric measurements and laboratory tests were performed. Atherogenic and insulin resistance indices were calculated.

\section{Results}

We did not find any differences in serum osteoprotegerin concentrations between overweight and obese children and their lean peers. In all studied patients, together with elevated quartiles of osteoprotegerin concentration, insulin resistance status decreased, and low-density lipoprotein cholesterol concentration increased. In the group of overweight and obese children osteoprotegerin was associated with low-density lipoprotein cholesterol, total cholesterol, and non high-density lipoprotein cholesterol. In the multiple linear regression analysis osteoprotegerin correlated only with low-density lipoprotein cholesterol $(\beta=0.140, p=0.005)$.

\section{Conclusions}

Insulin resistance and lipid profile seem to influence circulating osteoprotegerin levels, but most likely needs more time to change its concentration in overweight and obese patients. The association of osteoprotegerin with low-density lipoprotein cholesterol may suggest its link with atherogenesis. 


\section{Introduction}

Overweight and obesity in children and adolescents are serious health problems, responsible for an atherogenic lipid profile, insulin resistance, diabetes mellitus type 2 , hypertension and, in the long term, cardiovascular diseases. Excess adiposity also impacts liver function, the musculoskeletal system, as well as bone metabolism, increasing the risk of the development of osteoporosis [1-4].

A low-grade systemic inflammation, termed "metabolic inflammation," plays a crucial role in the etiology of cardiometabolic disorders [2,5]. Hypertrophied adipocytes, resident lymphocytes and macrophages produce and secrete many hormones, cytokines and chemokines, which activate multiple signaling pathways affecting systemic inflammation, immunity, glucose and lipid metabolism, angiogenesis and hemostasis. Despite the wellknown endocrine and immune function of adipose tissue (AT), the pathogenesis of ATrelated disturbances is still a very active field of research. There is a hormonal cross-link between AT and bone. Proinflammatory cytokines, especially tumor necrosis factor alfa (TNF $\alpha$ ) and Interleukins 1 and 6 (IL-1, IL-6) regulate the expression of the osteoprotegerin/receptor activator of nuclear factor- $\kappa \beta$ ligand (OPG/RANKL) system [6-8]. Moreover, OPG was found to have an inverse relationship with leptin [9] and a direct relationship with adiponectin [10].

Osteoprotegerin is a secretory glycoprotein belonging to the tumor necrosis factor (TNF) receptor superfamily and is composed of 401 amino acids containing 7 domains. OPG is produced by a variety of tissues, primarily in osteoblasts and bone marrow stromal cells, but its expression was also confirmed in AT [8,11]. It is well known as an important regulator of osteoclastogenesis. By binding the receptor activator of nuclear factor- $\kappa \beta$ ligand (RANKL), OPG blocks its interaction with Receptor Activator for Nuclear Factor NF- Kappa 
B (RANK) expressed on the membrane of osteoclast precursors and inhibits the differentiation and maturation of osteoclasts, thus inhibiting bone resorption $[7,8,11,12]$. The intensity of the process of bone remodeling depends on the balance between OPG and RANKL. The OPG/RANKL ratio can also be modulated by glucocorticoids, parathormone (PTH), 1,25 dihydroxyvitamin D and prostaglandin E2, which increase bone resorption and diminish bone density, and also transform growth factors (TGF- $\beta$ ) and estrogens, which have a protective effect $[7,8]$.

Studies have suggested that OPG, by interplay with other ligands, are implicated in various biological processes [12]. OPG can influence immune and inflammation processes and, by blocking TNF-related apoptosis ligand (TRAIL), may be involved in promoting cancer cell survival $[4,12]$. Moreover, OPG is expressed by endothelial cells and vascular smooth muscle cells thus having an impact on the vascular system [11]. A link has been suggested between OPG and vascular calcification, atherosclerosis and the pathogenesis of cardiovascular diseases [13-15]. The mechanism of this effect is not clear and seems to involve multiple players beyond RANKL and TRAIL [12]. In clinical trials evaluating the adult population, elevated OPG levels were found to be positively correlated with traditional risk factors of cardiovascular disease (CVD) such as smoking, hypercholesterolemia, hypertension, diabetes, metabolic syndrome, microalbuminuria, as well as with incidents of CVD and mortality [13-21]. OPG is considered to be a biomarker of endothelial cell dysfunction $[15,16,22,23]$. In adults with obesity, decreased levels of OPG in circulation have been reported [10,24,25], but this finding is not present in every patient [26]. Moreover, data concerning the association between serum OPG and cardiometabolic abnormalities related to fat mass are scarce and inconsistent $[10,13,24-26]$, especially in the pediatric population $[9,27-29]$. 
Therefore, the purpose of this study was to evaluate whether excess fat mass affects serum OPG concentrations and to evaluate its associations with chosen cardiometabolic risk factors in overweight and obese children and adolescents.

\section{Material and methods}

This study was performed in the Department of Paediatrics and Endocrinology at the Medical University of Warsaw. We recruited 105 children and adolescences ranging from 7.0 to 17.8 years of age. Thirty-five of them ( 21 girls, 14 boys, mean age $13.8 \pm 2.8$ years) were healthy with normal physical parameters. The remaining 70 children ( 36 girls, 34 boys, mean age $13.0 \pm 2.8$ ) had excess fatty mass. According to the values of z-score BMI, 17 patients met the criteria for being overweight ( $\mathrm{z}$-score $\mathrm{BMI} \geq 1)$, and 53 were obese ( $\mathrm{z}$-score $\mathrm{BMI} \geq 2)$.

All patients had a negative history of severe chronic disease and did not take any medications regularly, including vitamin D. Genetic and endocrine causes of excess fat mass, as well as diabetes, hypertension and hepatic and renal disturbances were excluded in all overweight and obese children.

This study received approval from the Ethical Committee at the Medical University of Warsaw. Informed consent was obtained from legal guardians of all participants and also from children older than 16 years.

Anthropometric measurements

The children enrolled in the study underwent anthropometric measurements: height $(\mathrm{cm})$, body weight $(\mathrm{kg})$, waist circumference and hip circumference $(\mathrm{cm})$, and thickness of skinfolds $(\mathrm{mm})$ : under the triceps brachii muscle and under the inferior scapular angle. Wearing only underwear, body weight was measured by means of medical scales to the nearest $0.1 \mathrm{~kg}$, and height by means of a stadiometer (Holtain Limited) to the nearest $0.1 \mathrm{~cm}$. 
Measurements of waist and hip circumference using a metric tape measure and thickness of skinfolds using a skinfold caliper Harpenden type were done according to the recommendations of the World Health Organization (WHO) [30]. The measurements were taken by a qualified anthropologist twice, then the results were averaged.

The obtained data were used to calculate body mass index (BMI), z -score BMI (SDS BMI, standard deviation score) by means of the LMS (lambda, mu, sigma) method to normalize the data for age and sex using polish reference values [31,32], waist to hip ratio (WHR), waist to height ratio (WHtR) as well as the percentage of fat tissue (\%BFM) from the sum of 2 skinfolds using the Slaughter formula [33]. Additionally, in overweight and obese children body composition was estimated by bioelectrical impedance analysis using the Maltron Body Fat Analyzer BF-905.

Laboratory analysis

Osteoprotegerin (OPG), soluble nuclear factor kappa B ligand (sRANKL), glucose and insulin, acute-phase protein (CRP) and uric acid concentrations, as well as lipid profile and calcium-phosphate metabolism parameters were measured in peripheral blood serum with the patient in a fasting state. Moreover, in overweight and obese children a standard oral glucose test (OGTT) was carried out.

OPG (pmol/l) and total sRANKL (pmol/l) concentrations were measured using an enzyme immunoassay - ELISA test (DRG Instruments GmbH, Germany). Total cholesterol (TC, mg/dl), high-density lipoprotein cholesterol (HDL-C, mg/dl) and triglyceride (TG, $\mathrm{mg} / \mathrm{dl}$ ) concentrations were determined by the calorimetric enzymatic method using the VITROS 5600 Chemistry Analyzer (Ortho-Clinical Diagnostics, USA). Glucose concentrations were carried out on the same analyzer using the glucose oxidase colorimetric method. Low-density lipoprotein cholesterol concentration (LDL-C, mg/dl) was calculated 
using the Friedewald formula [34]. Serum concentrations of insulin were determined by immunoassay using an IMMULITE 2000 Xpi Analyzer (Siemens, Erlangen, Germany).

Calcium $(\mathrm{Ca}, \mathrm{mg} / \mathrm{dl})$ and phosphorus $(\mathrm{P}, \mathrm{mg} / \mathrm{dl})$ levels and total alkaline phosphatase (ALP, U/L) activity in blood serum, as well as CRP $(\mathrm{mg} / \mathrm{dl})$ and urid acid $(\mathrm{mg} / \mathrm{dl})$ were measured by the dry chemistry system using a VITROS 5600 Chemistry Analyzer. The concentrations of intact parathyroid hormone $(\mathrm{PTH}, \mathrm{pg} / \mathrm{ml})$ and 25-hydroxyvitamin $\mathrm{D}$ (25(OH)D, ng/ml) were determined by immunoassay using a IMMULITE 2000 Xpi Analyzer and ARCHITECT Analyzer (Abbott Diagnostics; Abbott Park, IL), respectively.

Results of lipid profiles were interpreted according to the American Heart Association [35]. Based on the obtained data, the atherogenic indices TG/HDL-C ratio and non-HDL cholesterol (calculated as TC minus HDL-C) were calculated [36,37]. Homeostasis model assessment for insulin resistance index (HOMA-IR), fasting insulin to glucose ratio (I/G) and quantitative insulin sensitivity check index (QUICKI) were assessed for the evaluation of insulin resistance status [38]. A fasting insulin level of $\geq 15.0 \mu \mathrm{IU} / \mathrm{ml}$ [38], HOMA-IR $\geq 3.0$ [39], I/G > 0.3 [40] and QUICKI < 0.34 [41] were adopted as values indicative of insulin resistance.

Statistical analysis

Detailed statistical calculations were performed using SPPS 13.1 software. ShapiroWilk test was used to check the normality of distribution. Data were presented as means and standard deviation (SD) or median with interquartile range (IQR), as appropriate. For a better understanding and to explore the role of OPG in obesity, study participants were stratified according to quartiles of OPG. The obtained data were also analyzed between overweight and obese children and their healthy, lean peers. Depending on the distribution of the studied variables, a Student's T-test or U Mann-Whitney test was performed to compare the two 
groups. When comparing more than three groups, One-Way Analysis of Variance (ANOVA) or a Kruskal- Wallis test was used. To precisely assess which groups stratified according to quartiles of serum OPG levels, Tukey post-hoc tests with Bonferroni corrections were made for the ANOVA test and U-Mann-Whitney test for the KruskalWallis test. Relationship analyses were performed using the Spearman's rank correlation coefficient. In order to assess the influence of selected anthropometric and laboratory parameters on serum OPG concentration, a multivariable linear regression analysis was used. To accept or reject the statistical hypothesis a materiality level corresponding to a probability level of $\mathrm{p}<0,05$ was assumed.

\section{Results}

Biochemical characteristic of study population

Serum concentrations of $\mathrm{Ca}$ and $\mathrm{P}$ were within the normal range in all studied children and adolescents. Fifty-six (53.3\%) of them had 25(OH)D concentrations below 20 ng/ml, most of whom (44 children, $78.6 \%$ ) were with excess fat mass. Forty-two (40\%) children had 25(OH)D concentrations between $20-30 \mathrm{ng} / \mathrm{ml}$ (half lean and half overweight and obese), and only seven (6.7\%) children had concentrations above $30 \mathrm{ng} / \mathrm{ml}$. If we consider overweight and obese patients separately, most of them, $44(63 \%)$ had a significant deficiency below a 25(OH)D concentration of $20 \mathrm{ng} / \mathrm{dl}, 21(30 \%)$ between $20-30 \mathrm{ng} / \mathrm{dl}$ and, in general, they had higher median ALP activity as compared to normal weight children. In healthy, non-obese children, $12(34 \%)$ had 25(OH)D concentrations below $20 \mathrm{ng} / \mathrm{dl}$ and 21 (60\%) between 20-30 ng/dl. As we expected, overweight and obese children had a higher insulin resistance status and incorrect atherogenic lipid profiles as compared to non-obese children (data in Table I). Among them, increased fasting insulin concentrations $(\geq 15.0$ $\mu \mathrm{IU} / \mathrm{ml}), \mathrm{HOMA}-\mathrm{IR} \geq 3.0, \mathrm{I} / \mathrm{G}>0.3$ and QUICKI $<0.34$ were detected in $30(42.8 \%), 32$ 
(45.7\%), 9 (12.9\%) and 37 (52.8\%) overweight and obese individuals, respectively. Incorrect concentrations of HDL-C $(<40 \mathrm{mg} / \mathrm{dl})$ and TG $(\geq 110 \mathrm{mg} / \mathrm{dl})$ were detected in $21(30.0 \%)$ and $28(40.0 \%)$ children, respectively, in the same group. Moreover, overweight and obese children had significantly lower concentrations of sRANKL compared to the normal weight control group (median 276.95 vs $325.90, \mathrm{p}=0.011$ ). We did not find any differences in serum OPG concentrations between these two groups.

The comparison of selected anthropometric and biochemical parameters between healthy children with proper physical status and children with excess fat mass are presented in Table I.

OPG quartiles groups

After classifying all of the studied children into groups according to quartiles of OPG values (Table II) we observed that elevated quartiles of OPG concentration coincided with a decreased median of body weight, BMI, BMI SDS and \%BFM, but these changes were not statistically significant. We also found some dependencies of insulin resistance parameters on OPG. Children in the lower quartiles (Q1, Q2, Q3) of OPG concentrations had a higher median value of fasting insulin concentration, I/G ratio and HOMA-IR compared to children in the highest quartile (Q4) of OPG (Q1 vs Q4, Q2 vs Q4, Q3 vs Q4 for insulin: $\mathrm{p}=0.046$; $0.023 ; 0.046$ respectively, for $\mathrm{I} / \mathrm{G}$ ratio: $\mathrm{p}=0.039 ; 0.035 ; 0.053$, respectively, for HOMA: $\mathrm{p}$ $=0.056 ; 0.020 ; 0.035$, respectively). A similar observation applies to median PTH concentrations $(\mathrm{Q} 1$ vs $\mathrm{Q} 4, \mathrm{p}=0.030)$. Moreover, together with elevated quartiles of OPG we saw elevated mean concentrations of LDL-C (Q1 vs Q4, $\mathrm{p}=0.042)$, and TC (Q1 vs Q4, $\mathrm{p}=0.089)$.

When we analyzed the distribution of anthropometric and biochemical variables according to quartiles of OPG in the group of overweight and obese children only, we found 
elevated LDL-C and TC concentrations together with elevated quartiles of OPG levels (Table III). We also observed some changes in median HOMA-IR, TG/HDL-C ratio, nonHDL and PTH, but without statistical significance (Table III).

Correlation of OPG with anthropometric and biochemical parameters

In the Spearman correlation coefficient analysis, serum OPG weakly correlated with $\mathrm{I} / \mathrm{G}$ ratio $(\mathrm{R}=-0.23, \mathrm{p}=0.028), \operatorname{HOMA}-\mathrm{IR}(\mathrm{R}=-0.23, \mathrm{p}=0.030)$, $\mathrm{QUICKI}(\mathrm{R}=0.23, \mathrm{p}=$ $0.030)$ and $\mathrm{TC}(\mathrm{R}=0.24, \mathrm{p}=0.023)$ and LDL-C $(\mathrm{R}=0.27, \mathrm{p}=0.009)$ in all examined children. Based on results obtained from classifying all children into subgroups according to quartiles of OPG and Spearman coefficients, a multiple linear regression analysis was performed using OPG as the dependent variable and BMI, BMI SDS, \% BFM, PTH, TC, LDL-C, TG/HDL-C, I/G, HOMA-IR as the independent variables. We found that serum OPG was independently correlated with LDL-C $(\beta=0.062, p=0.004)$ and BMI SDS $(\beta=-$ $1.300, \mathrm{p}=0.076)$

In the group of overweight and obese children OPG correlated with PTH $(\mathrm{R}=-0.33$, $p=0.024), T C(R=0.29, p=0.016)$, LDL-C $(R=0.35, p=0.003)$, non-HDL $(R=0.27, p$ $=0.024)$. No correlation of OPG was observed with sRANKL, CRP, glucose and insulin levels during OGTT, insulin resistance indicis, nor Ca, P, ALP and 25(OH)D. In the multiple linear regression analysis where OPG was the dependent variable, we found a significant correlation with LDL-C $(\beta=0.140, \mathrm{p}=0.005)$ after taking into account PTH, TC, non-HDL, fasting insulin, HOMA-IR and TG/HDL-C ratio as the independent variables (Figure 1).

\section{Discussion}

In our study we did not find differences in serum OPG levels between overweight and obese children and adolescents and their normal weight peers. However, taking into account that children with excess fat mass had lower levels of sRANKL and consequently higher OPG/sRANKL ratio, our findings could suggest that fat excess favors the OPG 
pathway. The relationships between nutritional status, carbohydrate and lipid metabolism and OPG levels are not clear and reports available in literature are inconsistent. Yesilkaya et al [42] showed that there are no statistically significant differences in serum OPG and RANKL levels between obese and non-obese children and there are no associations between OPG and RANKL and weight SDS, BMI and BMI SDS. In our study of children and adolescents in a similar age range, in contrast to the above-mentioned results, we observed a tendency towards negative dependencies between OPG and body fat mass parameters. In a group of healthy children aged $0.5-19$ years it has been confirmed that serum OPG did not depend on age, sex, Tanner stage and physical state (height, weight and BMI percentile), while sRANKL levels positively correlated with age and body weight percentiles [43]. In studies conducted by Dimitri et al [9] and Erol et al [27] serum OPG levels were significantly lower in obese children and adolescents compared to non-obese controls, while Suliburska et al [28] found that obesity coincided with significantly higher OPG levels. Kotanidou et al [29] reported higher OPG levels in obese adolescents. They demonstrated that obese insulinresistant (IR) children exhibited significantly higher OPG levels compared to non-insulin resistant (non-IR) obese counterparts and compared to normal weight controls, which did not differ in regards to OPG concentrations [29]. Similar positive correlations between OPG levels and insulin resistance indices in obese children have been confirmed by Suliburska et al [28]. This suggests that serum OPG levels may be related to insulin resistance status, a finding that has also been highlighted in adult studies [18-20,25,44]. In our study we noticed an inverse relationship between serum OPG and insulin resistance parameters when looking at all of the studied participants as a whole. However, when taking into account only the overweight and obese children, those associations were not present. Some studies have also failed to show differences in OPG levels between obese insulin-resistant children and obese 
children with normal HOMA-IR values, as well as no correlation with HOMA-IR and QUICKI index [27,42]. The link between OPG and insulin resistance has not been clearly delineated. It is suggested that OPG may play a role in the pathogenesis of insulin resistance and diabetes through the inflammatory process [18-21].

The number of studies evaluating the relationship between serum OPG and lipid metabolism parameters are scare and mainly concern adults [21,22]. In 286 Korean women serum OPG levels were higher in those with increased concentrations of TC and LDL-C, with LDL-C being a positive predictor for OPG [45]. In another study consisting of 151 healthy men, serum OPG was negatively correlated with TG, however, the stepwise regression analysis did not confirm those findings [44]. Also, in a group of 106 obese patients, the positive association of OPG with TC and TG disappeared after adjustments were made for age [26]. Only Yesilkaya et al [42] analyzed the relationship between OPG and lipid profiles and atherogenic index in obese children, obtaining no statistical dependence. Our study was in agreement with the previously mentioned observations [45]. We found that OPG positively correlated with TC, LDL-C and non-HDL, but in a multiple linear regression analysis, after taking into account other factors that could affect the OPG levels, the only statistically significant relationship was found with LDL-C both in total participants and in the group of overweight and obese children. Infiltration and retention of LDL-C into the subendothelial space initiates an inflammatory response, macrophage infiltration, oxidative stress and cytokine/chemokine secretion. Inflammatory cytokines and injury to the endothelium activates cellular expression of OPG, which induces expression of adhesion molecules and promotes leucocyte adhesion [22,46]. It is implied that the participation of the OPG pathway in the development of atherosclerosis is initiated by elevated LDL-C. The exact mechanism underling the association between LDL-C and OPG 
is not clear [21]. Over time, the increased atherosclerotic burden and chronic inflammation will most likely cause the overexpression of OPG in endothelial cells, which was not overly present in our patients. The Tromso Study [47] including 6516 subjects aged 25-85 from the general population indicated that OPG increases significantly with carotid intima media thickness (cIMT) in older subjects and did not promote early atherosclerosis in younger participants.

The role of obesity in the regulation of circulating OPG levels is not clear. What is puzzling is the exact contribution of various tissue sources on serum OPG levels. In a study by Mista et al [48] including 43 girls with anorexia nervosa, the highest levels of OPG were found in those who had a bone density z-score lower than -1, while in girls with a normal bone density and comparable BMI, OPG values were lower and did not differ significantly from values in girls with a healthy weight. The authors [48] explained that elevated serum OPG levels in girls with anorexia nervosa may be due to a compensatory response to bone lose. Taking into account those observations, it is possible that in our study we did not observe differences in circulating OPG levels between children with excess fat mass compared to their normal weight peers, because they did not have reduced bone turnover and therefore did not require the protective effects of OPG. It is possible that higher total ALP activity in our overweight and obese children, and PTH concentrations comparable to normal weight participants, may point towards increased bone formation. On the other hand, most of the children in our study were undergoing puberty, during which growth hormone and sex steroids play a fundamental role in the formation of proper bone mass [49] and the negative impact of excess fat tissue and obesity related metabolic disturbances on bone metabolism will presumably be seen in the near future. 
The associations between OPG and obesity and metabolic disorders are multifactorial. In our study, next to insulin resistance, one of the main factors impacting circulating OPG levels appears to be LDL-C, which may suggest a link with atherogenesis. In the literature, relationships with adipocytokines, glucose metabolism, CRP, sex hormones status, markers of endothelial dysfunction and bone metabolism have also been documented $[6,7,9,10,13-16,25,26,44,47]$. Studies in adult populations emphasized that an elevated serum OPG level is interpreted as a compensatory mechanism to protect the body from the acceleration of atherosclerosis and bone resorption [44,45]. As is in accordance with the research of Yesilkaya et al [42], the conflicting results of the above-mentioned studies could indicate that longer exposure to obesity and metabolic disturbances could be required to produce clinical effects and changes in serum OPG levels. The main limitation of our study was the small sample size, which may explain some of the weak correlations and insignificant results. Further follow up studies including a larger group of children and adolescents are needed to explain those relationships.

\section{Conclusion}

In our study we did not find any differences in circulating OPG levels between overweight and obese children compared to their normal weight peers. We found relationships between OPG and insulin resistance as well as lipid profiles in the total study population. The association of serum OPG levels with LDL-C may explain its participation in the atherosclerotic process.

\section{Conflict of Interest Statement}

The authors declare no conflicts of interest in relation to this article.

\section{References}

1. Gregory JW. Prevention of obesity and metabolic syndrome in children. Front Endocrinol 2019;10: Article 669. 
2. Monteiro R, Azevedo I. Chronic Inflammation in Obesity and the Metabolic Syndrome. Hindawi 2010; Article ID 289645, 10 pages doi:10.1155/2010/289645.

3. Fintini D, Cianfarani S, Cofini M, Andreoletti A, Ubertini GM, Cappa M, Manco M. The Bones of Children With Obesity. Front Endocrinol 2020 Apr; 11: Article 200.

4. Faienza MF, D'Amato G, Chiarito M, Colaianni G, Colucci S, Grano M, Corbo F, Brunetti G. Mechanisms Involved in Childhood Obesity-Related Bone Fragility. Front Endocrinol 2019 May; 10: Article 269.

5. Makki K, Froguel P, Wolowczuk I. Adipose tissue in obesity-related inflammation and insulin resistance: cells, cytokines, and chemokines. ISRN Inflamm 2013 Dec 22; Article ID139239: 12 pages.

6. Cao JJ. Effects of obesity on bone metabolism. J Orthop Surg Res 2011 Jun 15; 6: 30.

7. Wright HL, McCarthy HS, Middleton J, Marshall MJ. RANK, RANKL and osteoprotegerin in bone biology and disease. Curr Rev Musculoskelet Med 2009; 2: 56-64.

8. Mikoś H, Mokoś M, Mokoś M, Obara-Moszyńska M, Niedziela M. Rola szlaku OPG/RANKL/RANK w otyłości u dzieci i młodzieży. Now Lek 2010; 79, 5: 403-409.

9. Dimitri P, Wales JK, Bishop N. Adipokines, bone-derived factors and bone turnover in obese children, evidence for altered fat-bone signaling resulting in reduce bone mass. Bone $2011 \mathrm{Feb} ; 48(2)$ : 189-196.

10. Ashley DT, O'Sullivan EP, Davenport C, Devlin N, Crowley RK, McCaffrey N, Moyna NM, Smith D, O'Gorman DJ. Similar to adiponectin, serum levels of osteoprotegerin are associated with obesity in healthy subjects. Metabolism 2011; 60(7): 994-1000.

11. Perez de Ciriza C, Lawrie A, Varo N. Osteoprotegerin in cardiometabolic disorders. Int J Endocrinol 2015; Article ID 564934: 15 pages.

12. Baud'huin M, Duplomb L, Teletchea S, Lamoureux F, Ruiz-Velasco C, Maillasson M, Redini F, Heymann MF, Heymann D. Osteoprotegerin: multiple partners for multiple functions. Cytokine Growth Factor Rev. 2013; 24(5): 401-409.

13. Omland T, Drazner MH, Ueland T, Abedin M, Murphy SA, Aukrust P, de Lemos DA. Plasma Osteoprotegerin Levels in the General Population Relation to Indices of Left Ventricular Structure and Function. Hypertension 2007; 49(6): 1392-1398.

14. Lieb W, Gona P, Larson MG, Massaro JM, Lipinska I, Keaney JF, Rong J, Corey D, Hoffmann U, Fox CS, Vasan RS, Benjamin EJ, O’Donnell ChJ, Kathiresan S. Biomarkers of the osteoprotegerin pathway: clinical correlates, subclinical disease, incident CVD and mortality. Arteroscler Thromb Vasc Biol 2010; 30(9): 1849-1854. 
15. Shin JY, Shin YG, Chung ChH. Elevated Serum Osteoprotegerin Levels Are Associated With Vascular Endothelial Dysfunction in Type 2 Diabetes. Diabetes Care 2006; 29(7): 16641666.

16. Berezin AE, Kremzer AA, Berezina TA, Martovitskaya YuV. The association of serum osteoprotegerin/ sRANKL complex, C-reactive protein and adiponectin with number of circulating endothelial progenitor cells in patients with metabolic syndrome and diabetes mellitus. J Integr Cardiol 2015; 1(3): 69-75.

17. Niu Y, Yang Z, Li X, Zhang W, Lu S, Zhang H, Chen X, Zhu L, Xing Y, Ning G, Qin $\mathrm{L}, \mathrm{Su}$ Q. Association of osteoprotegerin with impaired glucose regulation and microalbuminuria: the REACTION study. BMC Endocrine Disorders 2015; $15: 75$ (pages 9).

18. Duan P, Yang M, Wei M, Liu J, Tu P. Serum osteoprotegerin is an potential biomarker of insulin resistance in Chinese postmenopausal women with prediabetes and type 2 diabetes. Int J Endocrinol 2017; Article ID 8724869: 8 pages.

19. Yaturu S, Rains J, Jain SK. Relationship of elevated osteoprotegerin with insulin resistance, CRP, ant TNF- $\alpha$ levels in men with type 2 diabetes. Cytokine 2008; 44: 168171.

20. Ayina CNA, Sobngwi E, Essoma M, Noubiap JJN, Boudou P, Ngoa LSE, Gautier JF. Osteoprotegerin in relation to insulin resistance and blood lipids in sub-Saharan African women with and without abdominal obesity. D\&MS 2015; 7:47

21. Özkalayci F, Gülmez Ö, Uĝur-Altun B, Pandi-Perumal RP, Altun A. The role od osteoprotegerin as a cardioprotective versus reactive inflammatory markers: the chicken or the egg paradox. Balkan Med J 2018; 35: 225-232.

22. Rochette L, Meloux A, Rigal E, Zeller M, Cottin Y, Vergely C. The Role of Osteoprotegerin and Its Ligands in Vascular Function. Int J Mol Sci 2019 Feb 6; 20(3): 705 .

23. Zampetti S, Lucantoni F, Pacifico L, Campagna G, Versacci P, Pierimarchi P, Buzzetti R. Association of OPG-RANKL ratio with left ventricular hypertrophy and geometric remodeling in male overweight/obese youths. J Endocrinol Invest 2019; 42: 427-434.

24. Zaky DSE, Ali AAF, Abd-Elraheem SE, Abdel-Moniem SH. Circulating Osteoprotegerin Level in Relation to Obesity in Middle Aged Females. International Journal of Prevention and Treatment 2019; 8(2): 41-45.

25. Ugur-Altun B, Altun A, Gerenli M, Tugrul A. The relationship between insulin resistance assessed by HOMA-IR and serum osteoprotegerin levels in obesity. Diabetes Res Clin Pract 2005; 68(3): 217-222.

26. Gannagé-Yared MH, Yaghi C, Habre B, Khalife S, Noun R, Germanos-Haddad M, Trak-Smayra V. Osteoprotegerin in relation to body weight, lipid parameters insulin 
sensitivity, adipocytokines, and C-reactive protein in obese and non-obese young individuals: results from both cross-sectional and interventional study. Eur J Endocrinol 2008; 158(3): 353-359.

27. Erol M, Gayret OB, Nacaroglu HT, Yigit O, Zengi O, Akkurt MS, Tasdemir M. Association of Osteoprotegerin with Obesity, Insulin Resistance and Non-Alcoholic Fatty Liver Disease in Children. Iran Red Crescent Med J 2016; 18(11): e41873.

28. Suliburska J, Bogdanski P, Gajewska E, Kalmus G, Sobieska M, Samborski W. The association of insulin resistance with serum osteoprotegerin in obese adolescents. J Physiol Biochem 2013; 69(4): 847-853.

29. Kotanidou EP, Kotanidis ChP, Giza S, Serbis A, Tsinopoulou VR, Karalazou P, Tzimagiorgis G, Galli-Tsinopoulou A. Osteoprotegerin increases parallel to insulin resistance in obese adolescents Endocr Res 2019; 44(1-2): 9-15.

30. WHO Expert Committee: Physical Status: The use and Interpretation of Anthropometry. WHO Technical Report Series 854. Geneva WHO 1995: 1-350.

31. Cole TJ. The LMS method for constructing normalized growth standard. Eur J Clin Nutr 1990; 44 (1), 45-60.

32. Kułaga Z, Litwin M, Tkaczyk M, Palczewska I, Zajączkowska M, Zwolińska D, Krynicki T, Wasilewska A, Moczulska A, Morawiec-Knysak A, Barwicka K, Grajda A, Gurzkowska B, Napieralska E. Polish 2010 growth references for school-aged children and adolescents. Eur J Pediatr 2011, 170: 599-609.

33. Slaughter MH, Lohman TG, Christ CB, Boileau RA. Skinfold equations for estimation of body fitness in children and youth. Hum Biol 1998; 60 (5): 709-723.

34. Cybulska B, Kłosiewicz-Latoszek L, Cichocka A. Zaburzenia lipidowe. Wydawnictwo Lekarskie PZWL. Warszawa 2006.

35. Hayman LL, Meininger JC, Daniels SR, et al. Primary prevention of cardiovascular disease in nursing practice: focus on children and youth: a scientific statement from the American Heart Association Committee on atherosclerosis, hypertension, and obesity in youth of the council on cardiovascular disease in the young, council on cardiovascular nursing, council on epidemiology and prevention, and council on nutrition, physical activity, and metabolism. Circulation 2007 Jul 17; 116(3): 344-357.

36. Krawczyk M, Rumińska M, Witkowska-Sędek E, Majcher A, Pyrżak B. Usefulness of the Triglycerides to High-Density Lipoprotein Cholesterol ratio (TG/HDL-C) in prediction of metabolic syndrome in Polish obese children and adolescents. Acta Biochim Pol 2018; 19, 65(4): 605-611. 
37. Srinivasan SR, Berenson LM and GS. Distribution and correlates of non- high density lipoprotein cholesterol in children: The Bogalusa Heart Study. Pediatrics 2002 Sep; 110 (3): e29.

38. Ten S, Maclaren N. Insulin resistance syndrome in children. J Clin Endocrinol Metab 2004; 89(6): 2526-2539.

39. Shashaj B, Luciano R, Contoli B, Morino GS, Spreghini MR, Rustico C, Sforza RW, Dallapiccola B, Manco M. Reference ranges of HOMA-IR in normal-weight and obese young Caucasians. Acta Diabetol 2016; 53(2): 251-260.

40. Wesołowski P, Wańkowicz Z. Insulinooporność - metody rozpoznawania i następstwa kliniczne. Nephrol Dial Pol 2011; 15: 243-246.

41. Katz A, Nambi SS, Mather K, Baron AD, Follmann DA, Sullivan G, Quon MJ. Quantitative insulin sensitivity check index: a simple, accurate method for assessing insulin sensitivity in humans. J Clin Endocrinol Metab 2000; 85(7): 2402-2410.

42. Yesilkaya E, Bideci A, Çamurdan O, Boyraz M, Vurucu S, Cinaz P. Association of osteoprotegerin and rankl levels with insulin resistance in pubertal obese children. Cent Eur J Med 2010; 5(2): 261-267.

43 Wasilewska A, Rybi-Szuminska AA, Zoch-Zwierz W. Serum osteoprotegrin (OPG) and receptor activator of nuclear factor kappaB (RANKL) in healthy children and adolescents $\mathbf{J}$ Pediatr Endocrinol Metab 2009; 22(12): 1099-1104.

44. Gannagé-Yared MH, Fares F, Semaan M, Khalife S, Jambart S. Circulating osteoprotegerin is correlated with lipid profile, insulin sensitivity, adiponectin and sex steroids in an ageing male population. Clin Endocrinol 2006; 64: 652-658.

45. Oh ES, Eun-Jung Rhee, Won Young Lee, Ki Hyun Baek, Kun Ho Yoon, Moo Il Kang, Eun Joo Yun, Cheol Young Park, Moon Gi Choi, Hyung Joon Yoo, Sung Woo Park: Circulating osteoprotegerin levels are associated with age, waist-to-hip ratio, serum total cholesterol, and low-density lipoprotein cholesterol levels in healthy Korean women. Metabolism 2005 Jan; 54 (1): 49-54.

46. Ference BA, Ginsberg HN, Graham I, Ray KK, Packard CHJ, Bruckert E, Hegele RA, Krauss RM, Raal FJ, Schunkert H, Watts GF, Borén J, Fazio S, Horton JD, Masana L, Nicholls SJ, Nordestgaard BG, van de Sluis B, Taskinen MR, Tokgözoglu L, Landmesser U, Laufs U, Wiklund O, Stock JK, Chapman MJ, Catapano AL. Low-density lipoproteins cause atherosclerotic cardiovascular disease. 1. Evidence from genetic, epidemiologic, and clinical studies. A consensus statement from the European Atherosclerosis Society Consensus Panel. Eur Heart J 2017 Aug 21; 38(32): 2456-2472.

47. Vik A, Mathiesen EB, Brox J, Wilsgaard T, Njølstad I, Jørgensen L, Hansen JB. Relation between serum osteoprotegerin and carotid intima media thickness in a general population - the Tromsø Study. J Thromb Haemost 2010; 8(10): 2133-2139. 
48. Misra M, Soyka LA, Miller KK, Herzog DB, Grinspoon S, de Chen D, Neubauer G, Klibanski A. Serum Osteoprotegerin in Adolescent Girls with Anorexia Nervosa. J Clin Endocrinol Metab 2003 Aug; 88(8): 3816-3822.

49. Stagi S, Cavalli L, Iurato Ch, Seminara S, Brandi ML, de Martino M. Bone metabolism in children and adolescents: main characteristics of the determinants of peak bone mass.

Clin Cases Miner Bone Metab 2013 Sep; 10(3): 172-179. 
Table I. The comparison of anthropometric measurements, OPG, sRANKL and biochemical parameters between overweight and obese children and their peer with normal weight.

\begin{tabular}{|c|c|c|c|}
\hline Variable & $\begin{array}{l}\text { Non-obese children } \\
(\mathrm{n}=35)\end{array}$ & $\begin{array}{l}\text { Overweight and obese } \\
\text { children } \\
(\mathrm{n}=70)\end{array}$ & $\mathrm{p}$ - value \\
\hline Height $(\mathrm{cm})$ & $159.8 \pm 13.6$ & $160.6 \pm 14.2$ & ns \\
\hline Body weight (kg) & $50.8 \pm 12.7$ & $77.0 \pm 21.0$ & $<0.001$ \\
\hline BMI (kg/m2) & $18.7(4.6)$ & $29.4(5.5)$ & $<0.001$ \\
\hline BMI SDS & $0.0(1.1)$ & $2.1(0.4)$ & $<0.001$ \\
\hline $\mathrm{WC}(\mathrm{cm})$ & $64.7 \pm 6.2$ & $87.9 \pm 10.5$ & $<0.001$ \\
\hline $\mathrm{HC}(\mathrm{cm})$ & $83.7 \pm 9.4$ & $103.1 \pm 13.0$ & $<0.001$ \\
\hline WHR & $0.8 \pm 0.0$ & $0.9 \pm 0.1$ & $<0.001$ \\
\hline WHtR & $0.4 \pm 0.0$ & $0.5 \pm 0.1$ & $<0.001$ \\
\hline$\%$ BFM (skinfold) & $26.4(8.1)$ & $34.8(7.4)$ & $<0.001$ \\
\hline$\%$ BFM (BIA) & - & $40.8 \pm 6.6$ & - \\
\hline OPG (pmol/l) & $3.74(1.58)$ & $3.61(1.36)$ & ns \\
\hline sRANKL (pmol/l) & $325.90(247.30)$ & $276.00(188.56)$ & 0.011 \\
\hline OPG/sRANKL & $0.01(0.01)$ & $0.02(0.02)$ & 0.013 \\
\hline fasting glucose $(\mathrm{mg} / \mathrm{dl})$ & $83.27 \pm 6.97$ & $85.85 \pm 6.45$ & ns \\
\hline fasting insulin $(\mu \mathrm{IU} / \mathrm{ml})$ & $8.49(7.92)$ & $13.10(11.77)$ & $<0.001$ \\
\hline $\mathrm{I} / \mathrm{G}$ & $0.10(0.10)$ & $0.15(0.12)$ & $<0.001$ \\
\hline HOMA -IR & $1.71(1.59)$ & $2.84(2.62)$ & $<0.001$ \\
\hline QUICKI & $0.35(0.06)$ & $0.33(0.04)$ & $<0.001$ \\
\hline $\mathrm{TC}(\mathrm{mg} / \mathrm{dl})$ & $153.09 \pm 23.77$ & $162.08 \pm 26.75$ & ns \\
\hline HDL-C (mg/dl) & $62.28 \pm 11.97$ & $45.65 \pm 11.68$ & $<0.001$ \\
\hline LDL-C (mg/dl) & $78.05 \pm 19.64$ & $93.36 \pm 25.51$ & 0.013 \\
\hline TG (mg/dl) & $63.00(18.00)$ & $104.00(34.00)$ & $<0.001$ \\
\hline TG/HDL-C & $1.00(0.40)$ & $2.32(1.85)$ & $<0.001$ \\
\hline non HDL & $90.81 \pm 20.34$ & $116.43 \pm 26.27$ & $<0.001$ \\
\hline Uric acid (mg/dl) & $4.34 \pm 1.17$ & $5.82 \pm 1.09$ & 0.001 \\
\hline $\mathrm{Ca}(\mathrm{mg} / \mathrm{dl})$ & $9.90(0.40)$ & $10.00(0.35)$ & $\mathrm{ns}$ \\
\hline $\mathrm{P}(\mathrm{mg} / \mathrm{dl})$ & $4.60 \pm 1.00$ & $4.92 \pm 0.78$ & $\mathrm{~ns}$ \\
\hline $25(\mathrm{OH}) \mathrm{D}(\mathrm{ng} / \mathrm{ml})$ & $22.80(7.40)$ & $17.80(10.70)$ & 0.025 \\
\hline ALP (U/L) & $110.00(133.00)$ & $170.00(138.00)$ & 0.032 \\
\hline PTH (pg/ml) & $20.60(20.00)$ & $21.80(25.80)$ & ns \\
\hline CRP (mg/dl) & $0.5(0.0)$ & $0.5(0.05)$ & ns \\
\hline
\end{tabular}

Data are presented as mean \pm standard deviation (SD) or median values with interquartile range (IGR) as appropriate.

BMI - body mass index, BMI SDS - body mass index standard deviation score, WC - waist circumference, HC - hip circumference, WHR - waist-to-hip ratio, WHtR - waist-to-height ratio, $\%$ BFM - $\%$ of body fat mass, BIA - Bioimpedance Analysis, OPG - osteoprotegerin, sRANKL - soluble nuclear factor kappa B ligand, OPG/sRANKL - osteoprotegerin to soluble nuclear factor kappa B ligand ratio, I/G - fasting insulin to glucose ratio, HOMA - IR- 
Homeostasis model assessment for insulin resistance index, QUICKI - quantitative insulin sensitivity check index, TC - total cholesterol, HDL-C - high-density lipoprotein cholesterol, LDL-C - low-density lipoprotein cholesterol, TG - triglycerides, TG/HDL-C - triglycerides to high-density lipoprotein cholesterol ratio, non-HDL - non high-density lipoprotein cholesterol, $\mathrm{Ca}$ - calcium, $\mathrm{P}$ - phosphorus, 25(OH)D - 25-hydroxy vitamin D, ALP - alkaline phosphatase, PTH - parathyroid hormone, CRP- acute-phase protein, ns - non significant 


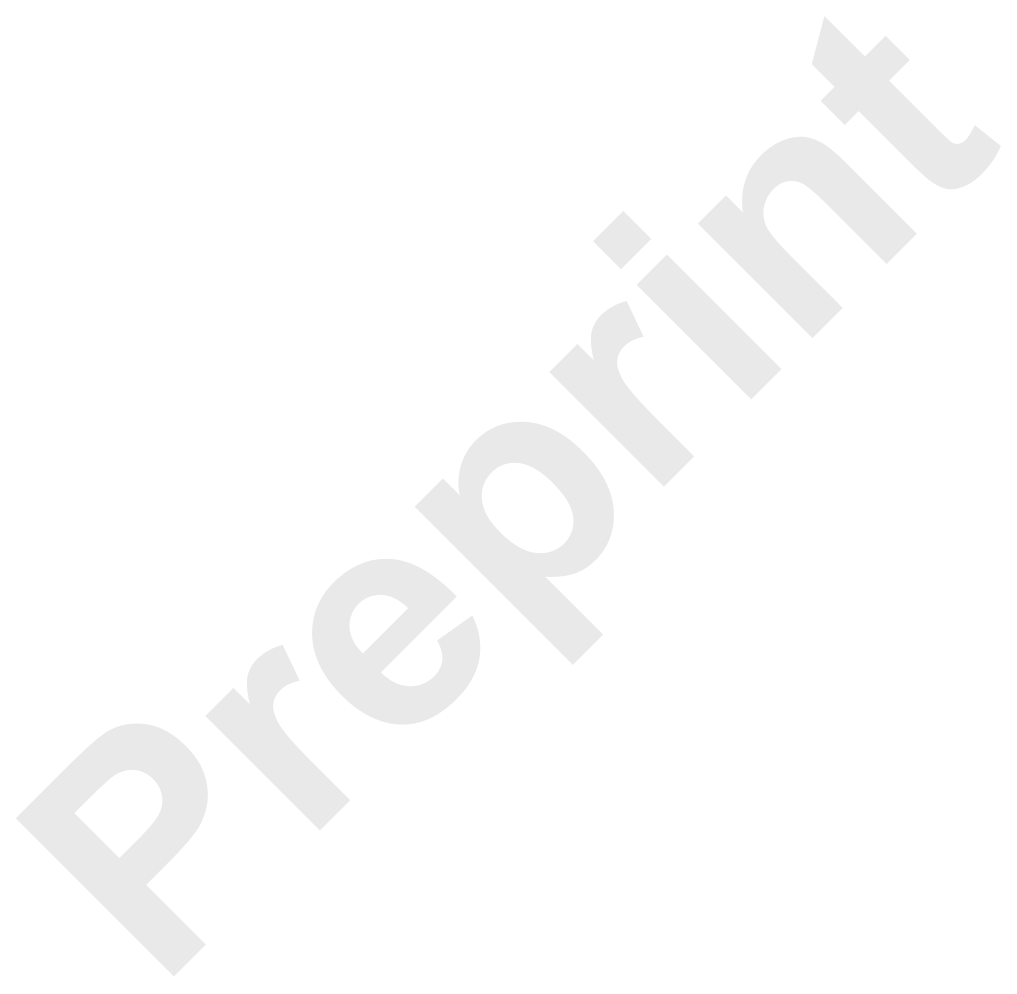


Table II. Characteristics of chosen anthropometric and biochemical parameters after stratification according to OPG quartiles in all studied children.

\begin{tabular}{|c|c|c|c|c|c|}
\hline Variable & $\begin{array}{l}\begin{array}{l}\text { Quartile 1 } \\
(\mathrm{n}=26)\end{array} \\
\end{array}$ & $\begin{array}{l}\text { Quartile 2 } \\
(\mathrm{n}=26)\end{array}$ & $\begin{array}{l}\text { Quartile } 3 \\
(\mathrm{n}=27)\end{array}$ & $\begin{array}{l}\text { Quartile } 4 \\
(\mathrm{n}=26)\end{array}$ & p-trend \\
\hline $\begin{array}{l}\text { OPG range }(\mathrm{pmol} / \mathrm{l}) \\
\text { Body weight }(\mathrm{kg}) \\
\text { BMI } \\
\text { BMI SDS } \\
\text { \%BFM (skinfold) } \\
\text { Fasting insulin }(\mu \mathrm{IU} / \mathrm{ml}) \\
\text { I/G } \\
\text { HOMA-IR } \\
\text { TC }(\mathrm{mg} / \mathrm{dl}) \\
\text { LDL-C }(\mathrm{mg} / \mathrm{dl}) \\
\text { TG/HDL-C } \\
\text { non HDL } \\
\text { PTH }(\mathrm{pg} / \mathrm{ml})\end{array}$ & $\begin{array}{l}<3.00 \\
70.1(59.1) \\
28.2(17.1) \\
2.0(3.6) \\
34.3(26.7) \\
14.35(32.00) \\
0.17(0.37) \\
2.95(6.77) \\
152.27 \pm 26.05 \\
82.51 \pm 25.98 \\
2.16(7.71) \\
103.55 \pm 28.25 \\
27.70(73.10)\end{array}$ & $\begin{array}{l}3.00-3.60 \\
67.2(73.3) \\
28.2(24.7) \\
2.1(4.3) \\
33.2(31.5) \\
11.70(47.87) \\
0.14(0.25) \\
2.64(10.93) \\
156.52 \pm 24.96 \\
85.15 \pm 24.06 \\
2.20(15.00) \\
108.87 \pm 25.03 \\
18.40(58.40)\end{array}$ & $\begin{array}{l}3.61-4.48 \\
60.0(96.7) \\
25.2(26.2) \\
2.0(4.2) \\
32.8(24.7) \\
11.65(22.50) \\
0.15(0.29) \\
2.46(4.94) \\
165.86 \pm 25.13 \\
93.13 \pm 20.09 \\
1.82(4.02) \\
114.55 \pm 23.77 \\
18.50(76.60)\end{array}$ & $\begin{array}{l}\geq 4.49 \\
53.3(89.6) \\
23.3(24.4) \\
1.2(3.7) \\
31.0(43.8) \\
8.83(91.30)^{* \# \wedge} \\
0.10(0.97)^{* \#} \\
1.87(21.05)^{\# \wedge} \\
167.90 \pm 26.80 \\
101.71 \pm 26.01^{*} \\
1.42(4.20) \\
118.14 \pm 30.53 \\
16.50(35.90)^{*}\end{array}$ & $\begin{array}{l}0.482 \\
0.605 \\
0.680 \\
0.299 \\
0.078 \\
0.092 \\
0.069 \\
0.147 \\
\mathbf{0 . 0 4 6} \\
0.666 \\
0.444 \\
0.177\end{array}$ \\
\hline
\end{tabular}

Data are presented as mean \pm standard deviation (SD) or median values with interquartile range (IGR) as appropriate.

OPG - osteoprotegerin, BMI - body mass index, BMI SDS - body mass index standard deviation score, \% BFM - \% of body fat mass, I/G - fasting insulin to glucose ratio, HOMA- IR - Homeostasis model assessment for insulin resistance index, TC - total cholesterol, LDL-C - low-density lipoprotein cholesterol, TG/HDL-C - triglycerides to high-density lipoprotein cholesterol ratio, non HDL - non high-density lipoprotein cholesterol, PTH - parathyroid hormone

* $\mathrm{p}<0.05$ found in comparison of Q1 to Q4 
\# $\mathrm{p}<0.05$ found in comparison of Q2 to Q4

$\wedge \mathrm{p}<0.05$ found in comparison of Q3 to Q4 
Table III. Characteristics of chosen anthropometric and biochemical parameters after stratification according to OPG quartiles in overweight and obese children

\begin{tabular}{l|lllll}
\hline Variable & $\begin{array}{l}\text { Quartile 1 } \\
(\mathrm{n}=18)\end{array}$ & $\begin{array}{l}\text { Quartile 2 } \\
(\mathrm{n}=17)\end{array}$ & $\begin{array}{l}\text { Quartile 3 } \\
(\mathrm{n}=18)\end{array}$ & $\begin{array}{l}\text { Quartile 4 } \\
(\mathrm{n}=17)\end{array}$ & $\mathrm{p}$-trend \\
\hline OPG range (pmol/l) & $<2.99$ & $2.99-3.60$ & $3.61-4.40$ & $\geq 4.41$ & \\
HOMA-IR & $3.15(6.7)$ & $2.71(10.4)$ & $2.58(4.7)$ & $2.37(21.0)$ & 0.676 \\
TC (mg/dl) & $151.53 \pm 25.23$ & $156.88 \pm 23.08$ & $168.89 \pm 24.07$ & $174.13 \pm 28.12$ & $\mathbf{0 . 0 4 4}$ \\
LDL-C (mg/dl) & $83.51 \pm 25.68$ & $87.00 \pm 22.63$ & $95.90 \pm 20.91$ & $110.43 \pm 24.65^{* \#}$ & $\mathbf{0 . 0 0 8}$ \\
TG/HDL-C & $2.50(7.70)$ & $2.30(14.10)$ & $2.20(4.40)$ & $2.20(3.70)$ & 0.740 \\
non-HDL & $106.41 \pm 28.70$ & $113.65 \pm 17.97$ & $119.78 \pm 25.00$ & $128.87 \pm 27.95$ & 0.080 \\
PTH (pg/ml) & $27.70(73.10)$ & $18.40(55.30)$ & $20.50(76.60)$ & $12.40(22.50)^{*}$ & 0.102 \\
& & & & & \\
\hline
\end{tabular}

Data are presented as mean \pm standard deviation (SD) median values with interquartile range (IGR) as appropriate.

OPG - osteoprotegerin, HOMA- IR - Homeostasis model assessment for insulin resistance index, TC - total cholesterol, LDL-C - low-density lipoprotein cholesterol, TG/HDL-C - triglycerides to high-density lipoprotein cholesterol ratio, non-HDL - non high-density lipoprotein cholesterol, PTH - parathyroid hormone

* $\mathrm{p}<0.05$ found in comparison of Q1 to Q4

\# $\mathrm{p}<0.05$ found in comparison of Q2 to Q4

$\wedge \mathrm{p}<0.05$ found in comparison of Q3 to Q4 


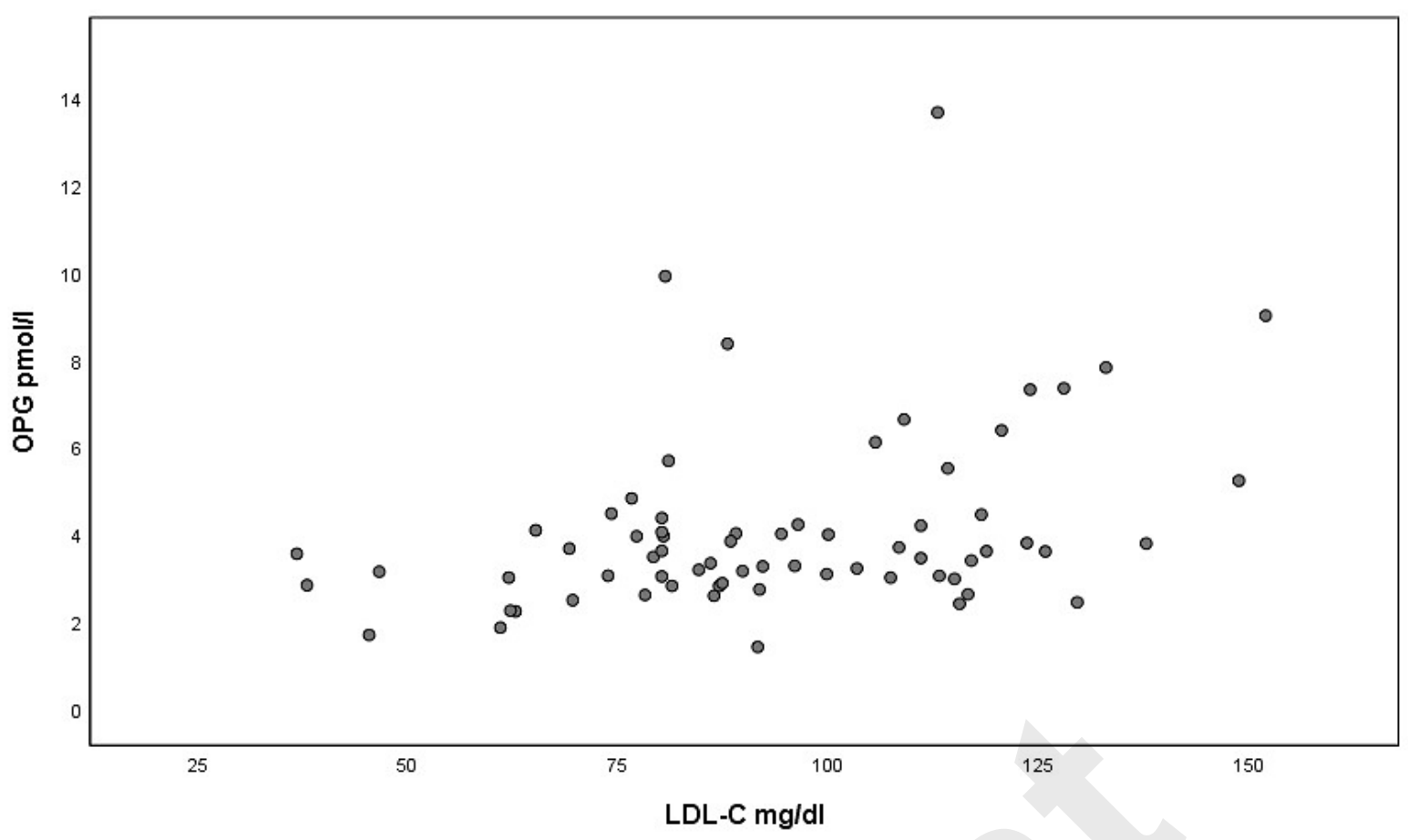

